\title{
ESTUDO DA PRODUÇÃO DE $\beta$-GALACTOSIDASE POR FERMENTAÇÃO DE SORO DE QUEIJO COM Kluyveromyces marxianus ${ }^{1}$
}

\author{
Patrícia A. SANTIAGO², Líbia D. S. MARQUEZ², Vicelma L. CARDOSO², Eloízio J. RIBEIRO2,*
}

\begin{abstract}
RESUMO
A hidrólise enzimática da lactose por $\beta$-galactosidase desempenha importante papel no processamento de produtos lácteos, como na obtenção de leite com baixo teor de lactose para consumo por indivíduos intolerantes à mesma e na prevenção da cristalização em produtos de laticínio. Neste trabalho, a enzima $\beta$-galactosidase foi produzida pelo cultivo do microrganismo Kluyveromyces marxianus, em meio de cultura à base de soro de queijo em diferentes concentrações iniciais de lactose e extrato de levedura, de acordo com um planejamento fatorial. As fermentações foram conduzidas em incubador rotativo a $150 \mathrm{rpm}$, a $30^{\circ} \mathrm{C}$ e pH inicial 5,5 . A concentração celular inicial foi de $10^{7}$ células $/ \mathrm{mL}$. Para a extração da enzima $\beta$-galactosidase, foi realizada autólise das células utilizando como solvente o clorofórmio em tampão fosfato. No meio de cultura enriquecido com $\left(\mathrm{NH}_{4}\right)_{2} \mathrm{SO}_{4}, \mathrm{KH}_{2} \mathrm{PO}_{4}$ e $\mathrm{MgSO}_{4}$, nas concentrações iniciais de lactose e de extrato de levedura iguais a $50 \mathrm{~g} / \mathrm{L}$ e $12 \mathrm{~g} / \mathrm{L}$, respectivamente, obteve-se uma atividade de $28,0 \mathrm{UGl} / \mathrm{mL}$ e uma concentração celular máxima de $5,3 \mathrm{~g} / \mathrm{L}$.

Palavras-chave: $\beta$-galactosidase; Kluyveromyces marxianus; soro de queijo; produção de $\beta$-galactosidase.
\end{abstract}

\section{SUMMARY}

SYNTHESIS OF $\beta$-GALACTOSIDASE BY FERMENTATION OF CHEESE WHEY BY Kluyveromyces marxianus. The enzymatic hydrolysis of lactose by $\beta$-galactosidase plays an important role in the processing of milky products such as the production of lactose-hydrolyzed milk for consumption by intolerant person to lactose and the prevention of the crystallization in dairy products. In this work, the influences of nutrient concentrations in the culture medium based on cheese whey were studied with the objective of producing b-galactosidase from Kluyveromyces marxianus. The fermentations were carried out in a shaker at $30^{\circ} \mathrm{C}$ and initial $\mathrm{pH} 5.5$ under agitation, starting with an initial cellular concentration of $10^{7}$ cells $/ \mathrm{mL}$, varying the initial concentrations of lactose and yeast extract. For extraction of the enzyme of the cells it was used autolysis with chloroform in potassium phosphate buffer. In the medium with a initial lactose concentration of $50 \mathrm{~g} / \mathrm{L}$, supplemented with salts, yeast extract $12 \mathrm{~g} / \mathrm{L}$, the enzymatic activity and cellular concentration were $28 \mathrm{UGl} / \mathrm{mL}$ and $5.3 \mathrm{~g} / \mathrm{L}$ respectively.

Keywords: $\beta$-galactosidase; Kluyveromyces marxianus; cheese whey; $\beta$-galactosidase production.

\section{1 - INTRODUÇÃO}

As $\beta$-galactosidases, popularmente conhecidas como lactases e classificadas como hidrolases, são responsáveis por catalisar o resíduo terminal $\beta$-galactopiranosil da lactose (Gal $\beta 1$ - 4Glc) para formar glicose e galactose $[3,6]$. As $\beta$-galactosidases podem ser encontradas na natureza, distribuídas entre vegetais - particularmente em amêndoas, pêssego, damasco, maçã -, em órgãos de animais, como intestino, cérebro, testículos, placenta e também são produzidas por grande quantidade de microrganismos, tais como fungos filamentosos, bactérias e leveduras [1, 5, 6], sendo as leveduras e fungos as fontes preferidas desta enzima para aplicações comerciais [7].

A importância industrial da $\beta$-galactosidase está na sua aplicação na indústria de laticínios. Esta enzima hidrolisa a lactose, carboidrato característico do leite e conhecido popularmente como "açúcar do leite", em seus monossacarídeos glicose e galactose, obtendo assim, alimentos com baixos teores de lactose, melhorando a solubilidade e digestibilidade do leite e deriva-

1. Recebido para publicação em 07/01/2003. Aceito para publicação em 19/08/2004 (001039).

2. Faculdade de Engenharia Química - Universidade Federal de Uberlândia CEP: 38400-902 - Caixa Postal 593 - Uberlândia- MG - BRASIL / Fone: (34) 3239-4291. Fax: (34) 3239-4188, E-mail: ejribeiro@ufu.br * A quem a correspondência deve ser enviada. dos lácteos, ideais para consumidores intolerantes à lactose $[7,10,11,13]$. A intolerância à lactose é definida como uma sindrome clínica de desconforto intestinal, também conhecida como Deficiência de Lactase do Adulto e ocorre devido aos baixos níveis (ou ausência) de atividade da enzima $\beta$-galactosidase no aparelho digestivo, conseqüência de uma deficiência congênita desta enzima ou de uma diminuição gradativa de sua atividade com o avanço da idade, causando sintomas como diarréia ácida e gasosa, fortes dores abdominais e inchaços [20].

Além dessa vantagem, a hidrólise da lactose previne sua cristalização em produtos lácteos como doce de leite, leite condensado, leite concentrado congelado, misturas para sorvetes e iogurtes e melhora as características organolépticas destes alimentos como cor e sabor. A hidrólise deste açúcar também aumenta a facilidade de corte e dá cremosidade às misturas para sorvete, diminui o tempo de maturação dos queijos Manchego e Cheddar, além de aumentar em cerca de $10 \%$ a produção dos queijos Cottage e Guark [10, 11] e produzir oligossacarídeos [1, 5, 7, 15]. Esta enzima tem sido usada preferencialmente na forma livre nas indústrias de laticínio em todo o mundo, porém em função de seu custo relativamente elevado, tem havido grande interesse na imobilização de $\beta$-galactosidase, porém até o momento não se obteve um catalisador com todas as propriedades desejadas para uso industrial $[7,8,9,18]$. Uma outra alternativa é a redução do custo de produção na síntese da enzima, utilizando 
meios de cultura mais baratos, tais como o soro de queijo $[4,12,16]$.

Com base na importância desta enzima na indústria alimentícia, o objetivo geral deste trabalho foi estudar a influência da composição do meio de cultura à base de soro de queijo no crescimento da levedura Kluyveromyces marxianus e na produção da enzima $\beta$ galactosidase.

\section{2 - MATERIAIS E MÉTODOS}

\section{1 - Materiais}

\subsection{1 - Microrganismo}

O microrganismo utilizado no presente trabalho foi Kluyveromyces marxianus ATCC 46537, proveniente da Coleção de Culturas Tropicais da Fundação André Tosello de Campinas (SP), na forma liofilizada. As cepas foram mantidas a $4^{\circ} \mathrm{C}$, em tubos de ensaio inclinado, contendo meio de cultura composto por ágar dextrose sabouraud a $65,0 g / \mathrm{L}$.

\subsection{2 - Meios de cultura}

O soro de queijo utilizado nos experimentos foi fornecido pela Fábrica de Produtos Alimentícios Vigor S/A, na forma desidratada, com a seguinte composição química mínima: $72 \%$ de lactose, $11 \%$ de proteína total, $8 \%$ de sais minerais. No preparo dos meios, o soro foi dissolvido em água destilada para as concentrações desejadas de lactose e, então suplementado com extrato de levedura nas concentrações de 0,0, 6,0 ou 12,0g/L (Tabela 1) e sais nas concentrações fixas de $6,0 \mathrm{~g} / \mathrm{L}$ de $\left(\mathrm{NH}_{4}\right)_{2} \mathrm{SO}_{4}, 5,0 \mathrm{~g} / \mathrm{L}$ de $\mathrm{KH}_{2} \mathrm{PO}_{4}$ e $0,6 \mathrm{~g} / \mathrm{L}$ de $\mathrm{MgSO}_{4} .7 \mathrm{H}_{2} \mathrm{O}$. A importância da suplementação dos meios com os sais citados anteriormente e com extrato de levedura foi estudada em trabalho anterior [17]. Antes de ser utilizado nas fermentações, o soro de queijo, após dissolução em água para atingir a concentração desejada de lactose, passou por um pré-tratamento para desproteinização por acidificação, com aquecimento a $93^{\circ} \mathrm{C}$ e adição de ácido lático até $\mathrm{pH} 4,8$ [14]. Após a remoção da fração protéica por precipitação, os meios foram complementados com os sais e extrato de levedura, o pH corrigido para 5,5 com solução $\mathrm{NaOH}(4 \mathrm{~mol} / \mathrm{L})$ e esterilizados a $121^{\circ} \mathrm{C}$ por 15 minutos. A necessidade de suplementação do soro de queijo foi estudada anteriormente por SANTIAGO [17].

\subsection{3 - Fermentações}

As fermentações foram conduzidas em incubador rotativo, com pH inicial de 5,5, com a temperatura mantida a $30^{\circ} \mathrm{C}$, agitação de $150 \mathrm{rpm}$, iniciando a fermentação com uma concentração inicial de células de leveduras igual a $1 \times 10^{7}$ células $/ \mathrm{mL}$. As influências das concentrações da lactose (proveniente do soro de queijo) e extrato de levedura no meio foram estudadas com base num planejamento fatorial. O tempo de acompa- nhamento da fermentação foi de $12 \mathrm{~h}$ e, neste período foram retiradas amostras de 2 em 2 horas para determinação da concentração celular, concentração de lactose no meio e atividade enzimática. Os inóculos cresceram em meios de composição idêntica aos das respectivas fermentações.

\section{2 - Metodologia analitica}

\subsection{1 - Determinação de concentração celular e lactose}

O acompanhamento do crescimento celular da levedura Kluyveromyces marxianus ao longo das fermentações foi realizado pela determinação da massa seca. Uma amostra do meio em fermentação foi centrifugada, as células precipitadas foram lavadas, e secadas em estufa a $105^{\circ} \mathrm{C}$ por 24 horas. A lactose foi determinada como açúcares totais pelo método fenol - ácido sulfúrico $[2,16]$.

\subsection{2 - Extração de $\beta$-galactosidase das células de levedura}

Para a extração da $\beta$-galactosidase intracelular das células de Kluyveromyces marxianus, foi efetuada a autólise das mesmas, utilizando-se como solvente clorofórmio (PA), conforme procedimento descrito por NUNES, MASSAUGER \& MONTE ALEGRE [12]. Amostras de 80mL de meio fermentado eram centrifugadas em uma centrífuga Beckman Couter J-25, num campo gravitacional igual a 27200 g por 5 minutos e o decantado ressuspenso em tampão fosfato $(0,1 \mathrm{M}) \mathrm{pH} 6,6$, sendo novamente centrifugado nas mesmas condições. Este novo precipitado era dissolvido em $10 \mathrm{~mL}$ do mesmo tampão, ao qual se adicionava $0,2 \mathrm{~mL}$ de clorofórmio PA. Esta mistura era incubada a $37^{\circ} \mathrm{C}$, sob agitação de 150 rpm por 17 horas. Após este tempo, a suspensão era novamente centrifugada, sendo descartado o precipitado e o sobrenadante utilizado para determinar a atividade enzimática.

\subsection{3 - Determinação da atividade de $\beta$-galacto- sidase}

A atividade enzimática, em todos os experimentos, foi determinada pelo método das taxas iniciais da reação de hidrólise de lactose, através da dosagem da glicose produzida pelo método da glicose-oxidase [19]. A unidade de atividade usada no trabalho foi Unidade de Glicose produzida por minuto, por mililitro de suspensão enzimática $(\mathrm{UGl} / \mathrm{mL})$, definida como sendo $\mu \mathrm{mol}$ de glicose produzida por minuto, por mL de suspensão enzimática, com uma concentração inicial de lactose igual a $50,0 \mathrm{~g} / \mathrm{L}$, a temperatura de $30^{\circ} \mathrm{C}, \mathrm{pH}$ 6,5, em tampão lático. Este apresentou a seguinte composição (g/L): citrato de sódio dihidratado 0,795, ácido cítrico monohidratado $1,663, \mathrm{~K}_{2} \mathrm{SO}_{4} 0,180, \mathrm{~K}_{2} \mathrm{HPO}_{4}$

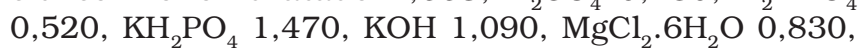
$\mathrm{CaCl}_{2} \cdot 2 \mathrm{H}_{2} \mathrm{O} 0,750, \mathrm{NaOH} 0,800, \mathrm{NaHCO}_{3} \mathrm{O}, 280$, com o $\mathrm{pH}$ ajustado em 6,5 com solução de ácido clorídrico $0,1 \mathrm{M}[17,19]$. 


\section{3 - RESULTADOS E DISCUSSÃO}

\section{1 - Influência da concentração de lactose e ex- trato de levedura na fermentação}

Com base nos resultados dos experimentos preliminares sobre a necessidade de suplementação dos meios de cultura obtidos por SANTIAGO [17], com os sais citados anteriormente e extrato de levedura, realizou-se um conjunto de nove experimentos, segundo um planejamento fatorial, $3^{\mathrm{K}}$ (onde $\mathrm{K}=2$ ), utilizando-se $\mathrm{o}$ software Statistica, versão 5,0, para tratamento dos dados. Através deste, estudou-se a influência das concentrações iniciais de lactose e de extrato de levedura no crescimento celular e na sintese de $\beta$-galactosidase.

Na Tabela 1 são apresentados os niveis selecionados para este planejamento e os máximos valores de concentração celular e atividade enzimática obtidos para os nove experimentos.

TABELA 1. Resultados de concentração celular e atividade enzimática máxima para os nove experimentos.

\begin{tabular}{ccccc}
\hline Experimento & $\begin{array}{c}\text { Concentração } \\
\text { inicial de } \\
\text { lactose }(\mathrm{g} / \mathrm{L})\end{array}$ & $\begin{array}{c}\text { Concentração } \\
\text { de extrato de } \\
\text { levedura }(\mathrm{g} / \mathrm{L})\end{array}$ & $\begin{array}{c}\text { Concentração } \\
\text { celular } \\
(\mathrm{g} / \mathrm{L})\end{array}$ & $\begin{array}{c}\text { Atividade } \\
\text { enzimática } \\
(\mathrm{UG} / \mathrm{mL})\end{array}$ \\
\hline 1 & 30,0 & 0,0 & 3,6 & 10,1 \\
2 & 30,0 & 6,0 & 4,6 & 12,0 \\
3 & 30,0 & 12,0 & 4,3 & 20,1 \\
4 & 50,0 & 0,0 & 4,0 & 12,0 \\
5 & 50,0 & 6,0 & 5,3 & 20,0 \\
6 & 50,0 & 12,0 & 5,3 & 28,0 \\
7 & 70,0 & 0,0 & 4,8 & 4,9 \\
8 & 70,0 & 6,0 & 6,6 & 19,2 \\
9 & 70,0 & 12,0 & 6,8 & 29,0 \\
\hline
\end{tabular}

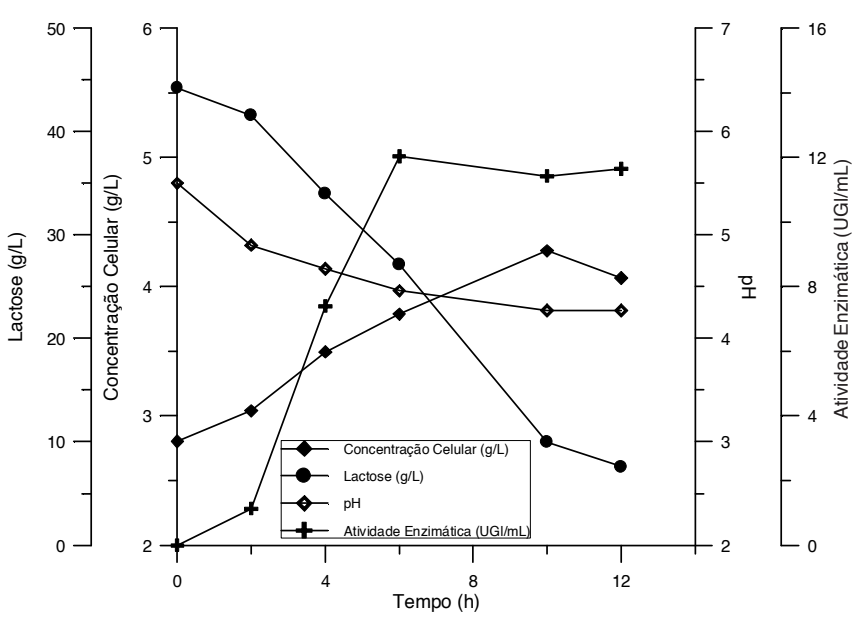

FIGURA 1. Fermentação de soro de queijo desproteinado por acidificação, suplementado de sais, com concentração inicial de lactose igual a 50,0g/L (experimento 4).

A seguir são apresentados os comportamentos cinéticos das fermentações relativas aos experimentos 4 e 6, como exemplos para uma condição de meio próxima ao soro in natura, sem extrato de levedura e su- plementado com a máxima concentração deste componente, respectivamente. Na Figura 1 são apresentados os perfis cinéticos relativos à fermentação realizada em incubador rotativo, em meio à base de soro de queijo desproteinado por acidificação, por Kluyveromyces marxianus, com concentração inicial de lactose de $50,0 \mathrm{~g} / \mathrm{L}$, suplementado com os sais nas concentrações citadas anteriormente e sem extrato de levedura.

Observa-se na Figura 1, que após 10 horas de fermentação a concentração celular atingiu 4,0g/L e a atividade enzimática alcançada foi de $12,0 \mathrm{UGl} / \mathrm{mL}$ após 6 horas, mantendo esse valor até o final da fermentação. A curva referente ao consumo de lactose mostra declínio até a décima segunda hora, quando a fermentação foi interrompida, restando cerca de $17 \%$ de lactose no meio.

A fermentação iniciou com pH 5,5 e, logo após a adição do inóculo esse valor foi decrescendo até atingir após 10 horas o valor 4,2, mantendo-se até o final do processo.

Na Figura 2 são apresentados os perfis cinéticos relativos à fermentação realizada em incubador rotativo, em meio à base de soro de queijo desproteinado por acidificação, por Kluyveromyces marxianus, com concentração inicial de lactose de 50,0g/L, suplementado com os sais nas concentrações citadas anteriormente e com extrato de levedura a $12,0 \mathrm{~g} / \mathrm{L}$, relativos ao experimento 6 .

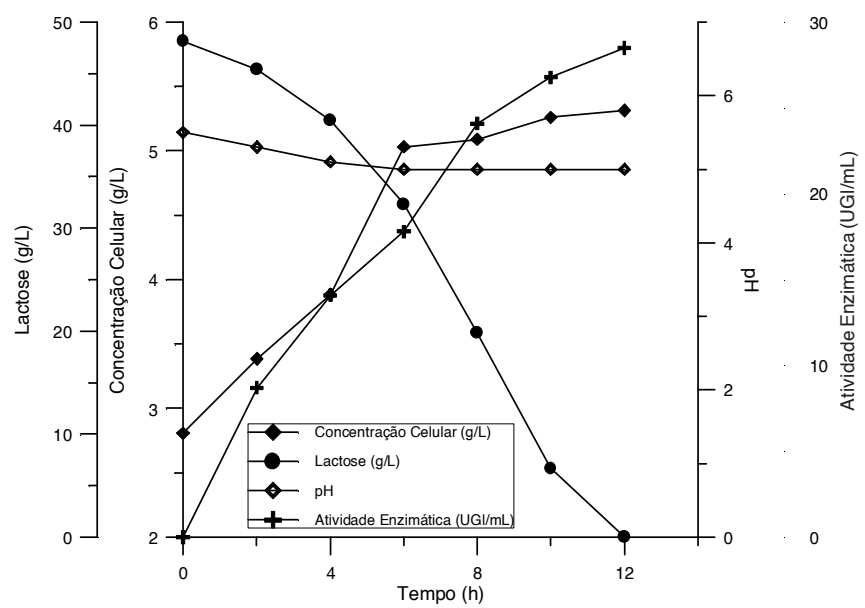

FIGURA 2. Fermentação de soro de queijo desproteinado por acidificação, suplementado com sais, com concentrações iniciais de lactose e extrato de levedura iguais a $50,0 \mathrm{~g} / \mathrm{L}$, e $12,0 \mathrm{~g} / \mathrm{L}$, respectivamente (experimento 6).

Pela análise dos resultados apresentados na Figura 2 , verifica-se que em 12 horas de fermentação, a concentração celular atingiu um valor de $5,3 \mathrm{~g} / \mathrm{L}$ e a atividade enzimática $28,0 \mathrm{UGl} / \mathrm{mL}$, sendo que a lactose do meio foi totalmente consumida e pelo comportamento das curvas, pode-se sugerir que a síntese da enzima é um processo associado ao crescimento celular. A fermentação iniciou com pH 5,2 após a adição do inóculo, e esse valor diminuiu até $\mathrm{pH}$ 5,0 após 6 horas de fermentação, mantendo-se constante até o final do processo. 
Analisando estas duas fermentações através de seus perfis cinéticos e através dos resultados do conjunto dos experimentos apresentados na Tabela 1, verifica-se que a adição de extrato de levedura favoreceu a sintese da enzima e o crescimento celular, quando comparada com o mesmo meio sem extrato, porém esta influência foi mais acentuada sobre a atividade enzimática. Conclui-se também que a presença de extrato de levedura no meio de cultura, no intervalo de concentrações estudado, contribuiu para estabilizar o valor de $\mathrm{pH}$ durante as fermentações e contribuiu para um maior consumo da lactose do meio.

\section{2 - Análise conjunta da influência da concentra- ção de lactose e extrato de levedura no crescimen- to da levedura e na sintese da enzima}

Com o objetivo de avaliar o efeito combinado da influência das concentrações de lactose e extrato de levedura sobre o crescimento celular e síntese de $\beta$-galactosidase, foram realizadas análises de superfícies respostas das variáveis codificadas (X para concentração de lactose e Y para a concentração de extrato de levedura) para os nove experimentos do planejamento fatorial, para a faixa de concentração de lactose de 30,0 a 70,0g/L e extrato de levedura variando de 0,0 a $12,0 \mathrm{~g} / \mathrm{L}$, apresentados nas Figuras 3 e 4 . As Tabelas 2 e 3 apresentam os resultados da regressão múltipla, com os valores dos parâmetros, os seus desvios padrões e os respectivos valores da estatística $t$ de Student, bem como os correspondentes niveis de significância (p).

TABELA 2. Resultados da regressão para a concentração celular.

\begin{tabular}{ccccc}
\hline Fator & Coeficiente & Desvio padrão & t de Student & $\mathrm{p}$ \\
\hline constante & 5,374 & 0,051 & 105,08 & $2,00 \cdot 10^{-6}$ \\
$\mathrm{X}$ & 0,945 & 0,028 & 33,72 & $5,70 \cdot 10^{-5}$ \\
$\mathrm{Y}$ & 0,681 & 0,028 & 24,31 & $1,53 \cdot 10^{-4}$ \\
$\mathrm{XY}$ & 0,312 & 0,034 & 9,09 & $2,81 \cdot 10^{-3}$ \\
$\mathrm{X}^{2}$ & 0,249 & 0,048 & 5,13 & $1,43 \cdot 10^{-2}$ \\
$\mathrm{Y}^{2}$ & $-0,736$ & 0,048 & $-15,17$ & $6,22 \cdot 10^{-4}$ \\
\hline $\mathrm{R}^{2}=0,998$ & & & &
\end{tabular}

TABELA 3. Resultados da regressão para a atividade enzimática.

\begin{tabular}{ccccc}
\hline Fator & Coeficiente & Desvio padrão & $\mathrm{t}$ de Student & $\mathrm{p}$ \\
\hline constante & 20,011 & 0,924 & 21,65 & $2,70 \cdot 10^{-5}$ \\
$\mathrm{X}$ & 1,818 & 0,653 & 2,78 & $4,96 \cdot 10^{-2}$ \\
$\mathrm{Y}$ & 8,356 & 0,653 & 12,79 & $2,15 \cdot 10^{-4}$ \\
$\mathrm{XY}$ & 3,548 & 0,800 & 4,43 & $1,14.10^{-2}$ \\
$\mathrm{X}^{2}$ & $-4,117$ & 1,131 & $-3,63$ & $2,20 \cdot 10^{-2}$ \\
\hline $\mathrm{R}^{2}=0,981$ & & &
\end{tabular}

Os parâmetros com níveis de significância maiores que 5\%, no teste de hipótese utilizando a distribuição t de Student, foram desprezados, ou seja, foi considerada uma probabilidade máxima de erro igual a 5\%. A Tabela 2 mostra que todas as variáveis influenciaram na concentração celular. Nos resultados de regressão, o termo quadrático relativo à concentração de extrato de levedura não teve influência significativa na atividade enzimática e não está presente nos resultados apresentados na Tabela 3 .

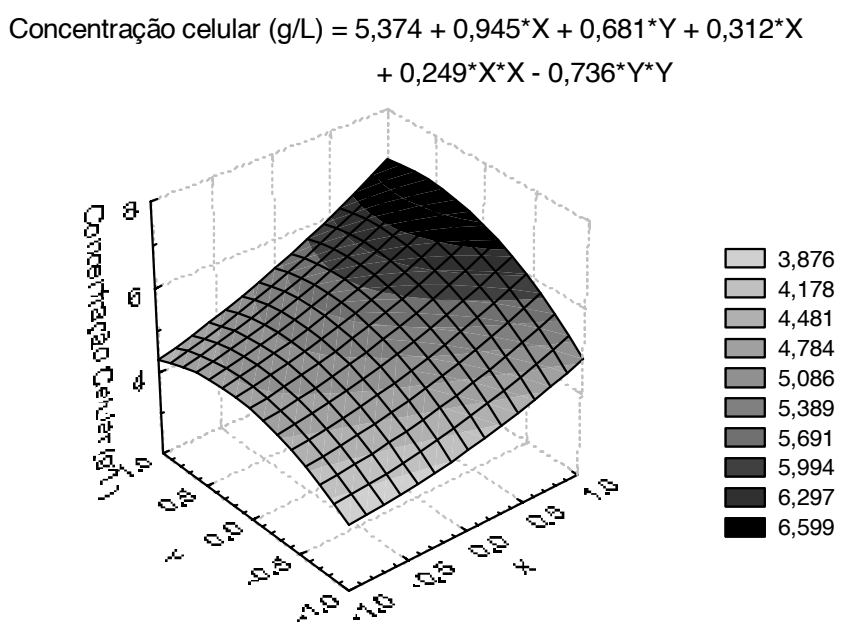

FIGURA 3. Concentração celular em função dos níveis codificados das concentrações iniciais de lactose (X) e extrato de levedura (Y).

Analisando a Figura 3, pode-se concluir que altas concentrações, tanto de lactose, como de extrato de levedura, contribuíram para o aumento da concentração celular no meio fermentativo.

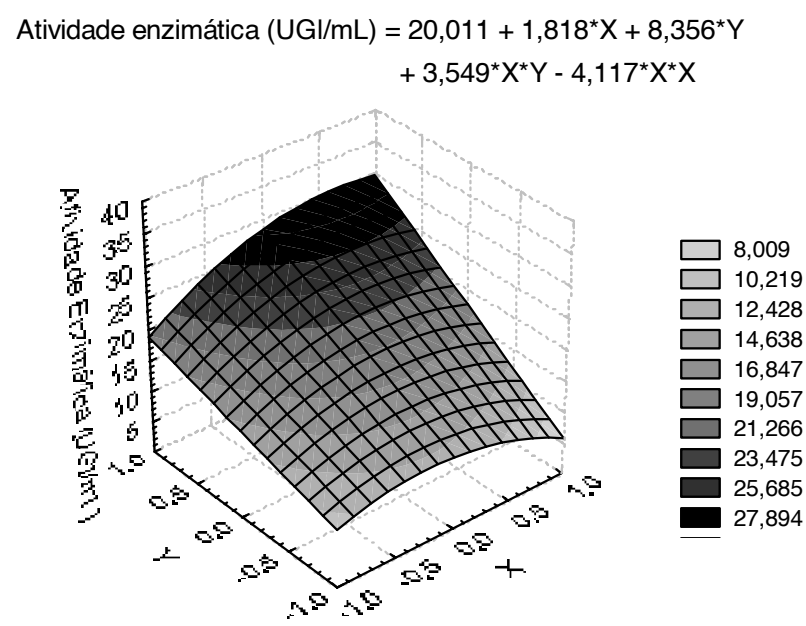

FIGURA 4. Atividade enzimática em função dos níveis codificados das concentrações iniciais de lactose (X) e extrato de levedura $(\mathrm{Y})$.

Analisando a Figura 4, observa-se que as maiores atividades enzimáticas foram obtidas utilizando concentrações iniciais de lactose na faixa de 50,0 a 70,0g/L e extrato de levedura de 6,0 a $12,0 \mathrm{~g} / \mathrm{L}$.

Com base nos experimentos realizados, pode-se concluir que a lactose constitui uma fonte de carbono adequada para o crescimento de Kluyveromyces marxianus ATCC 46537, com vistas à produção da enzima $\beta$-galactosidase. Meios de cultivo formulados à base soro de 
queijo necessitaram de suplementação com os sais $\left(\mathrm{NH}_{4}\right)_{2} \mathrm{SO}_{4}, \mathrm{KH}_{2} \mathrm{PO}_{4}$ e $\mathrm{MgSO}_{4} \cdot 7 \mathrm{H}_{2} \mathrm{O}$ e extrato de levedura para que houvesse crescimento e produção da enzima.

As concentrações de lactose entre 50,0 e 70,0g/L e de extrato de levedura de 6,0 a $12,0 \mathrm{~g} / \mathrm{L}$ favoreceram tanto o crescimento celular como a síntese da enzima. Verifica-se pela combinação das variáveis codificadas $\mathrm{X}$ (concentração de lactose) e Y (concentração de extrato de levedura), nas equações das Figuras 3 e 4, que a concentração de lactose tem uma influência mais acentuada no crescimento celular e a concentração de extrato de levedura na atividade enzimática. Comparando as atividades enzimáticas alcançadas com meios a base de soro a 50,0 e 70,0g/L de lactose, ambos complementados com extrato a $12,0 \mathrm{~g} / \mathrm{L}$, verifica-se que as mesmas foram praticamente iguais, o que sugere a utilização de soro a 50,0g/L de lactose, que é o mais próximo do soro in natura. Os resultados de atividade enzimática atingidos no presente trabalho foram similares ou superiores aos melhores resultados apresentados na literatura $[4,12,16]$.

\section{4 - CONCLUSÕES}

A partir dos resultados obtidos neste trabalho podese concluir que:

- Os meios de cultura contendo lactose como fonte de carbono, formulados com soro de queijo, se mostraram adequados para o crescimento da levedura Kluyveromyces marxianus ATCC 46537 e para a sintese da enzima $\beta$-galactosidase, desde que suplementados com nutrientes adequados.

- O soro de queijo constitui-se em um subproduto da indústria queijeira com grande potencial para ser utilizado como meio de cultura da levedura em questão, mostrando-se uma opção atrativa de custo muito menor que os meios sintéticos e uma alternativa para redução do poder poluente do mesmo.

- Com base nos resultados obtidos durante os ensaios verifica-se que a suplementação dos meios de cultura à base de soro de queijo com extrato de levedura permitiu atingir um maior crescimento celular e uma maior produção de $\beta$-galactosidase. Os melhores resultados de concentração celular e de atividade enzimática foram conseguidos com extrato de levedura na faixa de 6,0 a $12,0 \mathrm{~g} / \mathrm{L}$, em toda a faixa de concentração de lactose estudada. O extrato de levedura também contribuiu para uma menor queda no pH durante as fermentações.

- As maiores atividades enzimáticas obtidas no presente trabalho, da ordem de $29,0 \mathrm{UGl} / \mathrm{mL}$, foram alcançadas em meios com concentração de lactose na faixa de 50,0 a 70,0g/L e na maior concentração de extrato de levedura estudada, que foi $12,0 \mathrm{~g} / \mathrm{L}$.

\section{5 - REFERÊNCIAS BIBLIOGRÁFICAS}

[1] ALMEIDA, M.M.; PASTORE, G.M. Galactooligossacarídeos - Produção e efeitos benéficos. Boletim da So- ciedade Brasileira de Ciência e Tecnologia de Alimentos, v. 35, n. $1 / 2$, p. 12-19, 2001.

[2] BARALLE, S.B. Contribuição ao estudo da fermentação de soro de leite por Lactobacillus bulgaricus em processo descontínuo. São Paulo, 1985, 80p. Tese (Doutor em Microbiologia), Escola Paulista de Medicina (UNIFESP).

[3] BLANCH, H.W.; CLARK, D.S. Principles of catalysis. In: Biochemical Engineering. New York: Editora Marcel Dekker, 1997.

[4] FURLAN, S.A.; SCNEIDER, A.L.S.; MERKLE, R.; CARVALHO, J.M.F.; JONAS, R. Optmization of $\mathrm{pH}$, temperature and inoculum ratio for the production of beta-D-galactosidase by Kluyveromyces marxianus using a lactose-free medium. Acta Biotenologica, v. 21, n. 1, p. 57-64, 2001.

[5] GEKAS, V.; LOPEZ-LEIVA, M. Hidrolysis of lactose: A literature review. Process Biochemistry, v. 20, p. 2-12, 1985.

[6] HOLSINGER, V.H. Physical and chemical properties of lactose. In: Lactose, water, salts and vitamins. Advanced Dairy Chemistry, v. 3, p. 1-38, 1997.

[7] JURADO, E.; CAMACHO, F.; LUZÓN, G.; VICARIA, J. M. A new model proposed for hydrolysis of lactose by $\beta$-galactosidase from Kluyveromyces fragilis. Enzyme and Microbial Technology, v. 31, p. 300-309, 2002.

[8] LADERO, M.; SANTOS, A.; GARCIA, J.L.; GARCIAOCHOA, F. Activity over lactose and ONPG of a genetically engineered b-galactosidase from Escherichia coli in solution and immobilized: Kinetic modelling. Enzyme and Microbial Technology, v. 29, p.181-193, 2001.

[9] LADERO, M.; SANTOS, A.; GARCIA-OCHOA, F. Kinetic modeling of lactose hydrolysis with an immobilized $\beta$-galactosidase from Kluyveromyces fragilis. Enzyme and Microbial Technology, v. 27, p. 583-592, 2000.

[10] KARDEL, G.; FURTADO, M.M.; NETO, J.P.M.L. Lactase na indústria de laticínios. Revista do Instituto de Laticínios "Cândido Tostes", v. 50, n. 294, p. 15-17, 1995.

[11] MAHONEY, R.R. Lactose: Enzmatic modification. In: Lactose, water, salts and vitamins. Advanced Dairy Chemistry, v. 3, p. 77-125, 1997.

[12] NUNES, M.F.A.; MASSAUGER, S.; MONTE ALEGRE, R. Produção e propriedades de $\beta$-galactosidase de Kluyveromyces fragilis NRRL Y-2415. Revista Farmácia e Bioquímica da Universidade de São Paulo, v. 29, n. 1, p. 25-30, 1993.

[13] PIVARNIK, L.F.; SENEGAL, A.G.; RAND, A.G. Hydrolytic and transgalactosylic activities of commercial $\beta$-galactosidase (lactase) in food processing. Advances in Food and Nutrition Research, v. 38, p. 33-41, 1995.

[14] PORTO, L.M. Estudo e determinação das melhores condições operacionais do processo de produção da ricota. Belo Horizonte, 2001, 97p. Dissertação (Mestre em Engenharia Química), Departamento de Engenharia Química, Universidade Federal de Minas Gerais (UFMG).

[15] PRENOSIL, J.E.; STUKER, E.; BOURNE, J.R. Formation of oligosaccharides during enzymatic lactose: Part I: State of aArt. Biotechnology and Bioengineering, v. 30, p. 1019-1025, 1987.

[16] RECH, R. Aproveitamento do soro de queijo para a produção de lactase por Kluyveromyces marxianus. Porto Alegre, 1998. Dissertação (Mestre em Engenha- 
Produção de $\beta$-galactosidase por fermentação de soro de queijo com Kluyveromyces marxianus, Ribeiro et al.

ria Química), Departamento de Engenharia Química, Universidade Federal do Rio Grande do Sul (UFRGS).

[17] SANTIAGO, P.A. Contribuição ao estudo da produção de $\beta$-galactosidase por fermentação de soro de queijo com Kluyveromyces marxianus. Uberlândia, 2002. Dissertação (Mestre em Engenharia Química), Faculdade de Engenharia Química, Universidade Federal de Uberlândia (UFU).

[18] DI SERIO, M.; MATURO, C.; DE ALTERIS, E.; PARASCANDOLA, P.; TESSER, R.; SANTACESARIA,
E. Lactose hydrolysis by immobilized b-galactosidase: The effect of the supports and the kinetics. Catalysis Today, 79-80, p. 333-339, 2003.

[19] TOMÁS, C.M. Estudo da hidrólise da lactose por $\beta$-galactosidase na forma livre e imobilizada. Uberlândia, 1998, 69p. Dissertação (Mestre em Engenharia Química), Departamento de Engenharia Química, Universidade Federal de Uberlândia (UFU).

[20] White, A.; HANDleR, P.; SMITH, E. Princípios de bioquímica, $5^{\text {a }}$ edição. Rio de Janeiro: Guanabara Koogan, 1976. 